\title{
Crystal Structure of 2,3,7-Tris(cyclohexylimino)-3,4-dihydro-4- spirocycloheptan-2H-furo[3,4-b]pyran-5(7H)-one
}

\author{
Azizollah HABIBI, ${ }^{\dagger}$ and Enayatollah Sheikhhosseini LORI \\ Faculty of Chemistry, Tarbiat Moallem Uinversity, \\ No. 49, Mofateh Avenue, Tehran 15719-14911, Iran
}

\begin{abstract}
The title compound crystallized in triclinic space group $P \overline{1}$ with cell parameters $a=6.6634(3) \AA, b=12.3296(6) \AA c=$ $17.0338(8) \AA, \alpha=86.394(1)^{\circ}, \beta=81.052(1)^{\circ}, \gamma=85.002(1)^{\circ}, V=1375.43(11) \AA^{3}, Z=2, D_{\text {cal }}=1.226 \mathrm{Mg} / \mathrm{m}^{3}$ at $T=$ $100(2) \mathrm{K}$. The structure was refined by full-matrix least-squares procedures to find $R_{1}=0.0480$ and $w R_{2}=0.1143$ for 5663 reflections. All atoms in the furo-pyran ring are in a plane, except $\mathrm{C}_{6}$. All three cyclohexyl rings of isocyanides adapt chair conformation, and their plane alignment is noncoplanar with respect to furo-pyran plane. The spiro cycloheptyl ring has a chair conformation.
\end{abstract}

(Received April 25, 2009; Accepted October 14, 2009; Published on web February 10, 2010)

\begin{abstract}
Multi-component reactions (MCRs) have been extensively investigated in organic and diversity oriented synthesis, primarily due to their ability to generate complex functionality from simple starting materials in a one-step transformations. ${ }^{1,2}$ Great efforts have been, and still are made to find and develop new multi-component reactions. An isocyanide-based multicomponent reaction has a magic situation for providing a diversity oriented synthesis. Here, we introduce the crystal structure product of a multi-component $(3+1)$ reaction of isocyanide and alkylidene Meldrum's acid. ${ }^{3-6}$
\end{abstract}

The title compound was prepared by the reaction of cyclohexyl isocyanide and alkylidene Meldrum's acid (3:1 ratio) in dichloromethane at room temperature within four hours (Fig. 1). After evaporating the solvent, ethanol was added to the residue, and a white powder was separated from the reaction mixture. More purification and recrystallization was done in hot ethanol.

The crystal structure (Fig. 2) was solved by direct methods and refined on $F^{2}$ by full-matrix least-squares procedures. The title compound crystallized in triclinic space group $P \overline{1}$ with cell parameters $a=6.6634(3) \AA, b=12.3296(6) \AA, c=17.0338(8) \AA$, $\alpha=86.394(1)^{\circ}, \quad \beta=81.052(1)^{\circ}, \quad \gamma=85.002(1)^{\circ}, \quad V=$ $1375.43(11) \AA^{3}, Z=2, D_{\text {cal }}=1.226 \mathrm{Mg} / \mathrm{m}^{3}$ at $T=100(2) \mathrm{K}$. The non-hydrogens were refined anisotropically, and all of the hydrogens were fixed as a riding model over their heavier atoms.

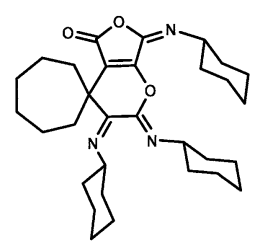

Fig. 1 Chemical diagram of the title compound.

† To whom correspondence should be addressed.

E-mail: habibi@.tmu.ac.ir; azhabibi81@yahoo.com
A fine cycle refinement $[I>2 \sigma(I)]$ converged to $R_{1}=0.0480$ and $w R_{2}=0.1143$ for the observed reflections $[I>2 \sigma(I)]$ is 5663 . Crystal data and other relevant parameters for the compound are given in Table 1. All atoms in the furo-pyran ring are in a plane; except for $\mathrm{C}_{6}$, all three cyclohexyl rings of isocyanides adapt to a chair conformation, and their plane aligns in a noncoplanar way with respect to the furo-pyran plane. The spiro cycloheptyl ring has a chair conformation. The bond lengths of the furopyran atoms are normal. Although the imine bond lengths of $\mathrm{N}(1)-\mathrm{C}(2)$ and $\mathrm{N}(2)-\mathrm{C}(5)$ are similar, the bond lengths of $\mathrm{N}(3)$ $\mathrm{C}(6)$ show a slight elongation. As a result, these bond lengths

Table 1 Crystal and experimental data

$$
\begin{aligned}
& \text { Chemical formula: } \mathrm{C}_{31} \mathrm{H}_{45} \mathrm{~N}_{3} \mathrm{O}_{3} \\
& \text { Formula weight }=507.70 \\
& T=100(2) \mathrm{K} \\
& \text { Crystal system: triclinic } \quad \text { Space group: } P \overline{1} \\
& a=6.6634(3) \AA \\
& b=12.3296(6) \AA \\
& c=17.0338(8) \AA \\
& V=1375.43(11) \AA^{3} \\
& D_{\mathrm{x}}=1.226 \mathrm{Mg} / \mathrm{m}^{3} \\
& \text { Radiation: } \operatorname{Mo} K_{\alpha}(\lambda=0.71073 \AA) \\
& \mu\left(\text { Mo } K_{\alpha}\right)=0.079 \mathrm{~mm}^{-1} \\
& \text { Crystal size }=0.44 \times 0.12 \times 0.10 \mathrm{~mm}^{3} \\
& \text { No. of reflections collected }=16875 \\
& \text { No. of independent reflections }=7286[R \text { (int })=0.0287] \\
& \theta \text { range for data collection: } 1.21 \text { to } 29.00^{\circ} \\
& \text { Data/Restraints/Parameters }=7286 / 0 / 334 \\
& \text { Goodness-of-fit on } F^{2}=1.023 \\
& R \text { indices }[I>2 \sigma(I)]: R 1=0.0480, w R 2=0.1143 \\
& R \text { indices (all data): } R 1=0.0656, w R 2=0.1252 \\
& \Delta \rho=0.001 \\
& (\Delta / \sigma)_{\max }=0.59 \mathrm{e} / \AA^{-3} \\
& (\Delta / \sigma)_{\max }=-0.58 \mathrm{e} / \AA^{-3} \\
& \text { Measurment: Bruker APEX-II CCD } \\
& \text { Program System: SHELXL-97, SADABS } \\
& \text { Structure Determination: SHELXS-97 } \\
& \text { CCDC deposition number: } 686152 \\
& \alpha=86.394(1)^{\circ} \\
& \beta=81.052(1)^{\circ} \\
& \gamma=85.002(1)^{\circ} \\
& Z=2 \\
& F\left(\begin{array}{lll}
0 & 0 & 0)
\end{array}\right)=552
\end{aligned}
$$


Table 2 Selected bond lengths $[\AA]$ and angles $\left[{ }^{\circ}\right]$ for the compound

\begin{tabular}{rrrr} 
O1-C2 & $1.3975(15)$ & O1-C1-C4 & $108.34(10)$ \\
O1-C1 & $1.4004(15)$ & N1-C2-O1 & $126.32(11)$ \\
O2-C1 & $1.1953(16)$ & N1-C2-C3 & $127.88(12)$ \\
O3-C3 & $1.3503(15)$ & O1-C2-C3 & $105.72(10)$ \\
O3-C5 & $1.4206(14)$ & C4-C3-O3 & $127.26(11)$ \\
N1-C2 & $1.2551(17)$ & C4-C3-C2 & $110.99(11)$ \\
N1-C14 & $1.4731(15)$ & O3-C3-C2 & $121.72(11)$ \\
N2-C5 & $1.2493(16)$ & C3-C4-C1 & $105.99(11)$ \\
N3-C6 & $1.2676(16)$ & C3-C4-C7 & $123.72(11)$ \\
N3-C26 & $1.4667(17)$ & O3-C5-C6 & $115.06(10)$ \\
C1-C4 & $1.4743(17)$ & N3-C6-C5 & $124.09(11)$ \\
C2-C3 & $1.4695(17)$ & N3-C6-C7 & $122.03(11)$ \\
C3-C4 & $1.3375(17)$ & C5-C6-C7 & $113.88(10)$ \\
C4-C7 & $1.5139(17)$ & C4-C7-C6 & $101.65(10)$ \\
C5-C6 & $1.5124(17)$ & C4-C7-C8 & $110.70(10)$ \\
C6-C7 & $1.5397(17)$ & C6-C7-C8 & $111.75(10)$ \\
& & C8-C7-C13 & $115.20(11)$ \\
& & C9-C8-C7 & $119.14(12)$ \\
& & N1-C14-C19 & $110.27(10)$ \\
& & N1-C14-C15 & $106.97(10)$ \\
& & C19-C14-C15 & $110.36(10)$ \\
& & C16-C15-C14 & $111.25(11)$ \\
& & C17-C16-C15 & $111.10(11)$ \\
& & C18-C17-C16 & $111.46(11)$ \\
& & C7-C18-C19 & $110.96(11)$ \\
\hline & &
\end{tabular}

are similar to those in other reports previously published, ${ }^{7}$ in which for the imine bond there is no resonance effect, or a very weak resonance effect may be exist. The plane of the three cyclohexyl rings aligns in a noncoplanar way with respect to the furo-pyran plane, due to a reduced repulsion of the crowded structure. The dihedral torsion angle of $\mathrm{N}(2)-\mathrm{C}(5)-\mathrm{C}(6)-\mathrm{N}(3)$ is $54.29^{\circ}$.

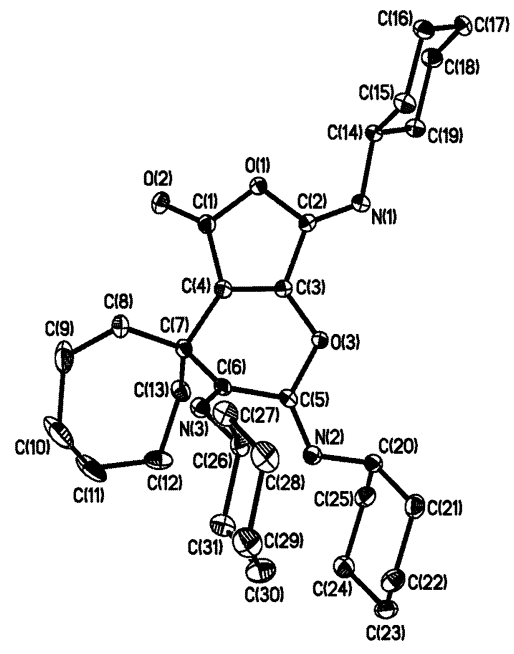

Fig. 2 Molecular structure (ORTEP-III plot) along with an arbitrary numbering of the atoms (thermal ellipsoids for non-hydrogen atoms).

2. A. Domling and I. Ugi, Angew. Chem. Int. Ed. Engl., 2000, 39,3168 .

3. A. N. Meldrum, J. Chem. Soc., 1908, 93, 598.

4. D. Davidson and S. A. Bernhard, J. Am. Chem. Soc., 1948 $70,3426$.

5. B. C. Chen, Heterocycles, 1991, 32, 529. H. McNab, Chem. Soc. Rev., 1978, 7, 354.

6. I. Yavari and A. Habibi, Synthesis, 2004, 7, 989 and references cited therein.

7. H. Hartung, A. Stettler, and W. Weissflog, J. Mole. Struct., 2000, 526, 31; I. Kilic, F. Ersahin, E. Agar, and S. Isik, $X$ Ray Struct. Anal. Online, 2009, 25, 25; J. Li, Z.-P. Liang, F.-T. Kong, H. Zhang, and X.-S. Tai, Chinese J. Struct. Chem., 2009, 28(5), 577.

\section{References}

1. I. Ugi, Angew. Chem. Int. Ed. Engl., 1982, 21, 810. 